Article

\title{
Green Compact Temperature Evolution during Current-Activated Tip-Based Sintering (CATS) of Nickel
}

\author{
Ahmed El Desouky ${ }^{1}$, Kee S. Moon ${ }^{2}$, Samuel K. Kassegne ${ }^{2}$ and Khaled Morsi ${ }^{2, *}$ \\ 1 Department of Materials Science and Engineering, Egypt Japan University of Science and \\ Technology, Alexandria, Egypt; E-Mail: ahmed.eldesouky@ejust.edu.eg \\ 2 Department of Mechanical Engineering, San Diego State University, San Diego, CA 92182, USA; \\ E-Mails: kmoon@mail.sdsu.edu (K.S.M.); kassegne@mail.sdsu.edu (S.K.K.) \\ * Author to whom correspondence should be addressed; E-Mail: kmorsi@mail.sdsu.edu; \\ Tel.: +1-619-594-2903; Fax: +1-619-594-3599.
}

Received: 22 December 2012; in revised form: 17 March 2013 / Accepted: 25 March 2013 / Published: 15 April 2013

\begin{abstract}
Current-activated tip-based sintering (CATS) is a novel process where spark plasma sintering conditions are applied through an electrically conducting tip on a locally controlled area on a green powder compact/bed. The localization of electric current in CATS allows for unique temporal and spatial current and temperature distributions within the tip and powder compact. In this paper, special experimental setups were used to monitor the temperature profiles in the tip and at multiple locations on the surface of nickel powder compacts. A variation in the initial green density was found to have a significant effect on the maximum temperature in the tip as well as the temperature distribution across the powder compact. In general, the lowest green density specimens displayed the best conditions for localized densification. The concept of effective current density is introduced and results are discussed in relation to the densification parameter.
\end{abstract}

Keywords: current activated tip-based sintering; spark plasma sintering; temperature distribution; nickel

\section{Introduction}

Despite the intense research and interest in spark plasma sintering (SPS) as a fast powder consolidation process, other methods have emerged combining the effect of electric current with 
plastic deformation such as electric rolling of powders [1,2] and spark plasma extrusion [3,4]. Most recently, current-activated tip-based sintering (CATS) [5] developed by the authors, has provided the means to localize SPS conditions, and open the door to multi-scale processing of $1 \mathrm{D}, 2 \mathrm{D}$ and $3 \mathrm{D}$ shapes.

CATS is a new process in which an electric current is allowed to pass through a small conducting tip (that could be stationary or moving) to a powder compact/bed thus enforcing SPS conditions on a locally controlled area depending on the size and shape of the tip. Figure 1 shows a schematic of a CATS setup.

Figure 1. Schematic of a CATS setup.

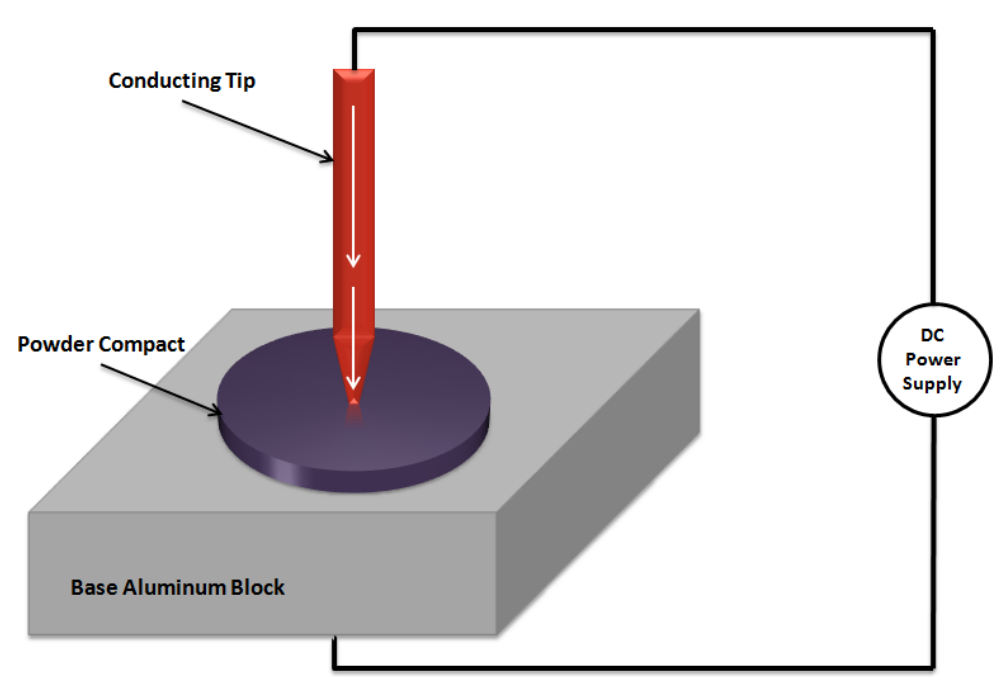

Recently, CATS has been used to locally sinter different material systems such as nickel and copper powders [6], as well as Ni-Ti intermetallics [7]. It was also recently used to enable an ignition of a macro-scale current-activated combustion synthesis process for $\mathrm{Ni}-\mathrm{Al}$ powder mixtures which would spontaneously convert to an intermetallic phase [8]. Due to the potentially small tip sizes used in CATS, it can be extremely difficult to obtain temperature measurements through conventional routes such as those used in SPS. This is also due to the absence of a die in CATS; moreover, optical pyrometers are excluded due to spot size limitations. Therefore, it was necessary to introduce an experimental setup that allows for monitoring of spatial and temporal temperature distributions. This paper, therefore, for the first time, provides an initial insight into the expected temperature distributions in green compacts and tips during CATS. In this work, temperatures from the surface of the tip, as well as the green compact, were taken using high response thermocouples that were placed at pre-specified exact locations using specially designed devices. Due to the inherent tip-specimen geometry in CATS and the very small thickness of the specimens, it was impossible to obtain subsurface temperature measurements. The concept of effective current density is introduced and the densification parameter was used to explain results for specimens of varying green densities (with different starting resistivity values) that undergo CATS. 


\section{Experimental Section}

Nickel powder (INCO type 123) with $5 \mu \mathrm{m}$ average particle size (Figure 2) was used in all the experiments. The powders were compacted in a $12 \mathrm{~mm}$ inner diameter steel die to different initial green densities ranging from $55 \%-76 \%$ of theoretical density of nickel $\left(8.9 \mathrm{~g} / \mathrm{cm}^{3}\right)$. All compacts had a thickness of $1 \mathrm{~mm}$ (squat specimens) to ensure minimum internal density variations within the specimens. Compacts that had a green density less than 55\% were excluded from the investigations due to their lack of adequate strength for handling.

Figure 2. Scanning electron micrograph of INCO 123 nickel powders.

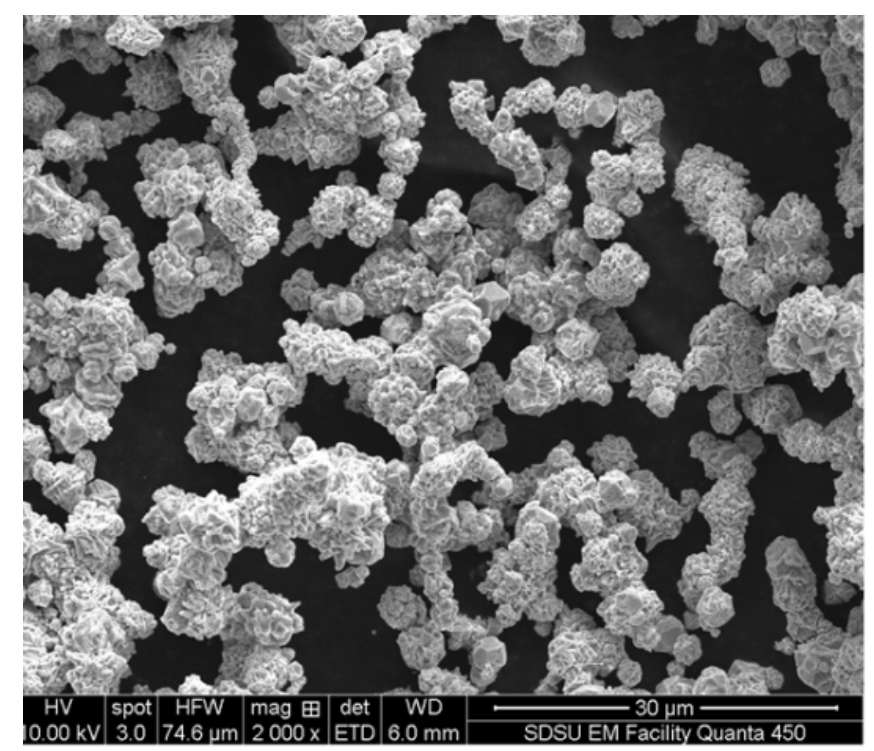

A direct "nominal" current density (applied current divided by the specimen-tip initial contact area) of $\sim 50,000 \mathrm{~A} / \mathrm{cm}^{2}$ (using a power supply, Power Ten, Model P63C-51000) was applied through a conducting $0.5 \mathrm{~mm}$ diameter flat CATS tip (with a pressure of $\sim 5 \mathrm{MPa}$ ) for $60 \mathrm{~s}$ on all investigated green densities in an inert argon atmosphere. A special device was designed to enable temperature measurements using K-type thermocouples at different radial locations from the tip circumference on the top surface of the powder compact as seen in Figure 3 (taking advantage of the axi-symmetric nature of the setup). The base aluminum block had to be modified so that the tip positioning is central to ensure that all three thermocouples are properly spaced and to ensure positioning repeatability. Other experiments were also conducted using flat tip K-type thermocouples cemented on the sintering tip at a $\sim 2.5 \mathrm{~mm}$ distance from the tip-compact interface (Figure 4) and a data acquisition system (PDAQ view OMB-DAQ-55) was used to collect the temperature data from the thermocouples at a frequency of $2.88 \mathrm{~Hz}$. 
Figure 3. (a) Thermocouple holder with locating holes at different radial distances; (b) close-up photograph of tip-specimen-thermocouples configuration and (c) a photograph of the setup after all attachments are in place.

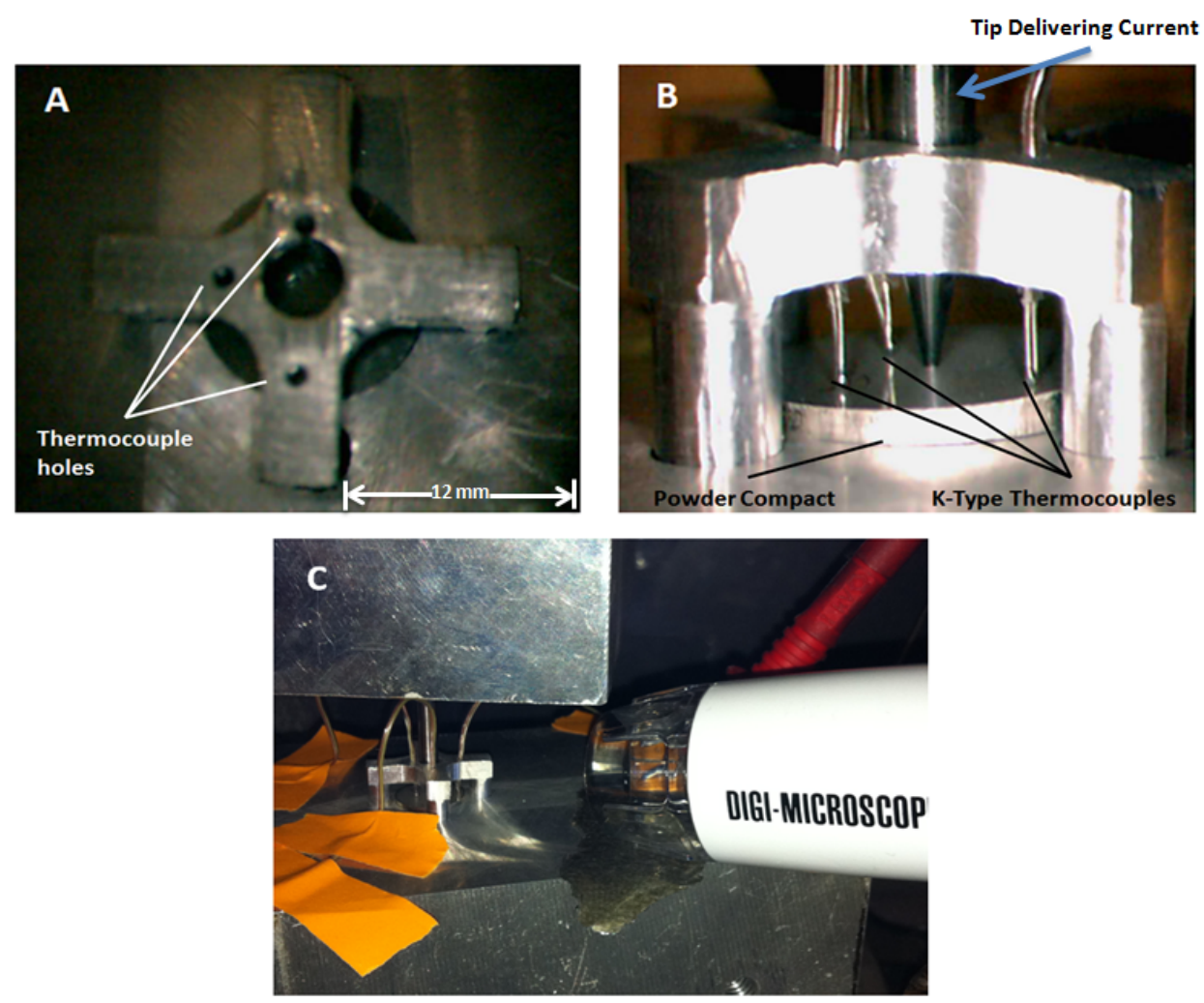

Figure 4. Flat-tip fast-response K-type thermocouple cemented on CATS tip.

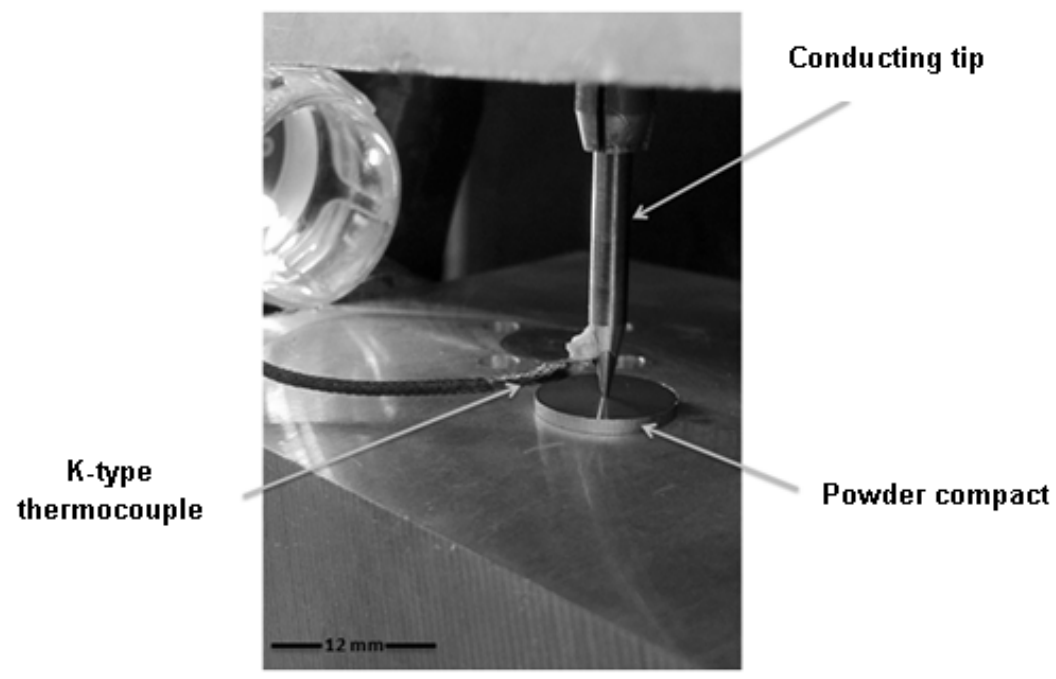

For microstructural characterization, the top surface of the processed specimens were lightly ground and polished to at least $1-\mu \mathrm{m}$ finish using diamond suspension. Microstructural characterization was conducted using a field emission scanning electron microscope (FESEM quanta FEG 450). Porosity contents were measured using image analysis software (UTHSCSA Image Tool version 3.0; Department of Dental Diagnostic Science at The University of Texas Health Science Center: San 
Antonio, TX, USA, 2002). Additionally, green densities were determined using mass and volume measurements.

\section{Results and Discussion}

Figure 5 shows temperature profiles during CATS (up to $60 \mathrm{~s}$ electric current exposure) of Ni 123 powder compacts with initial average green densities $\sim 55 \%, 67 \%$ and $76 \%$ of theoretical. Since the current is applied for only 60 seconds, in the figure, times greater than 60 seconds represent cooling curves in the absence of current. The "tip" temperatures at $\sim 2.5 \mathrm{~mm}$ away from the specimen surface were measured by using the thermocouple configuration shown in Figure 4. For all initial green densities investigated, the initial heating rate was found to be the same; however, higher temperatures were observed with a decline in green density. Steady state temperatures were reached for the $67 \%$ and $76 \%$ dense specimens within the duration of the experiment. This was not, however, the case for the lowest green density specimens where a continuously increasing temperature was observed within the investigated current exposure time. This could be explained if we consider the comparatively higher resistivity of these specimens. This high resistivity will give rise to comparatively higher temperatures immediately under the tip, leading to rapid consolidation of this local region. This consolidated region will possess a low resistivity, and therefore becomes highly electrically conductive. Thus, an electric current passing through the tip would now travel through the consolidated region (process zone) to the significantly unsintered (more resistive) areas beneath/around it. The surrounding area will then heat through Joule heating and that heat is then transferred to the tip through the already-consolidated region above it (in addition to other regions of the compact). This process is progressive in nature leading to the observed continuous increase in temperature, during the timeframe of the experiment. Such progressive growth of the process zone has also been previously documented for NiTi during CATS [6].

Figure 5. Temperature measurements taken from a thermocouple cemented on the CATS tip ( $2.5 \mathrm{~mm}$ away from tip-powder compact interface).

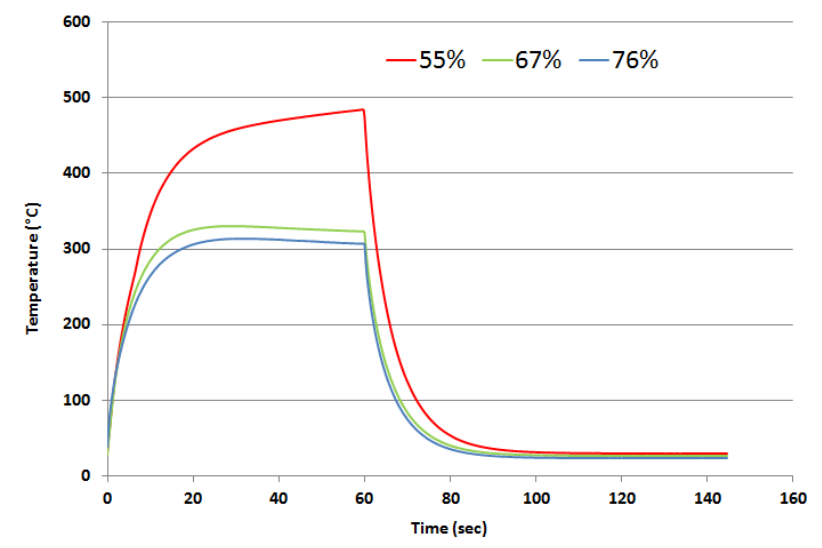

Separate experiments were also conducted for the same set of initial green densities. Here temperature measurements were instead taken on the powder compact surface at different radial distances (between $2.5 \mathrm{~mm}$ and $4.5 \mathrm{~mm}$ ) from the tip circumference. For all investigated green densities, the temperature was found to decline radially away from the tip location. Figure 6 a shows 
temperature profiles taken from the closest thermocouple to the tip $(\sim 2.5 \mathrm{~mm}$ away from the tip circumference). It shows that the maximum temperature was experienced by the lowest green density specimens as more heat generation is expected in the vicinity of the tip, while the $76 \%$ density specimen achieved a steady-state temperature higher than that of the $67 \%$ density. However, the temperature at this location in the $55 \%$ density specimens only becomes the highest after $\sim 43 \mathrm{~s}$ of current exposure. The reason for this behavior is simply due to the difference in thermal conductivity of the two specimens (the $55 \%$ being the lowest). Immediately under the tip, the $55 \%$ specimen is expected to have the highest temperature. However, at $2.5 \mathrm{~mm}$ away from the tip, due to its low thermal conductivity, it will take longer for the heat to travel to the thermocouple location, hence the behavior observed in the plot. Figure $6 \mathrm{~b}$ shows temperature profiles taken from the thermocouple that is farthest from the tip. However, at this location, the 55\% density specimen achieved the lowest temperature rise. This is again due to the lower thermal conductivity of the $55 \%$ green density compact compared to higher green density specimens. The results also show that the maximum temperature read by the thermocouples out of all the specimens was $\sim 140{ }^{\circ} \mathrm{C}$ at a distance $\sim 2.5 \mathrm{~mm}$ from the tip circumference. At such temperatures, nickel is not expected to sinter which therefore favors a localized consolidation effect only for regions much closer to the tip. Finite element modeling (the subject of another publication [9]) showed that the maximum temperature reached at the maximum temperature reached under the current conditions was close to $1000^{\circ} \mathrm{C}$.

Figure 6. Surface temperature profiles for nickel powder compacts with various initial green densities sintered with CATS at a distance (a) $\sim 2.5 \mathrm{~mm}$ and (b) $\sim 4.5$ away from the tip circumference.
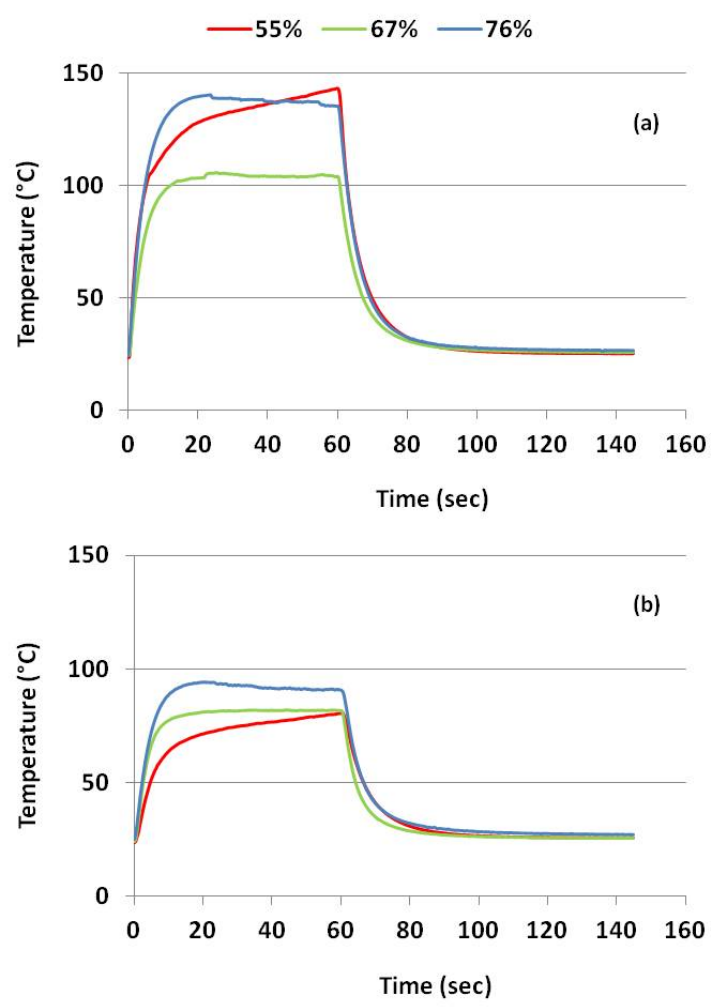
Figure 7 shows scanning electron micrographs of regions in the vicinity and under the tip for the $55 \%$ initial green density specimens. Some surface circular cracks were observed around the consolidated regions due to shrinkage and thermally induced stresses. However, it was observed that the radius, as well as the thickness of these cracks, decreased for the $67 \%$ density specimen as less shrinkage was experienced, while for the $76 \%$ density specimens (with an expected higher green strength), minimum shrinkage was observed and no circumferential cracks were detected. Further microscopic analysis showed that consolidation was mainly confined to the region immediately beneath the tip, and no consolidation took place in the area in between this region and the circular crack (since the observed microstructure was similar to that of the unsintered green compact) which is evidence of consolidation only being confined to the region under the tip.

Figure 7. Scanning electron micrograph of a 55\% initial green density specimen showing evident densification only at the area underneath the tip.

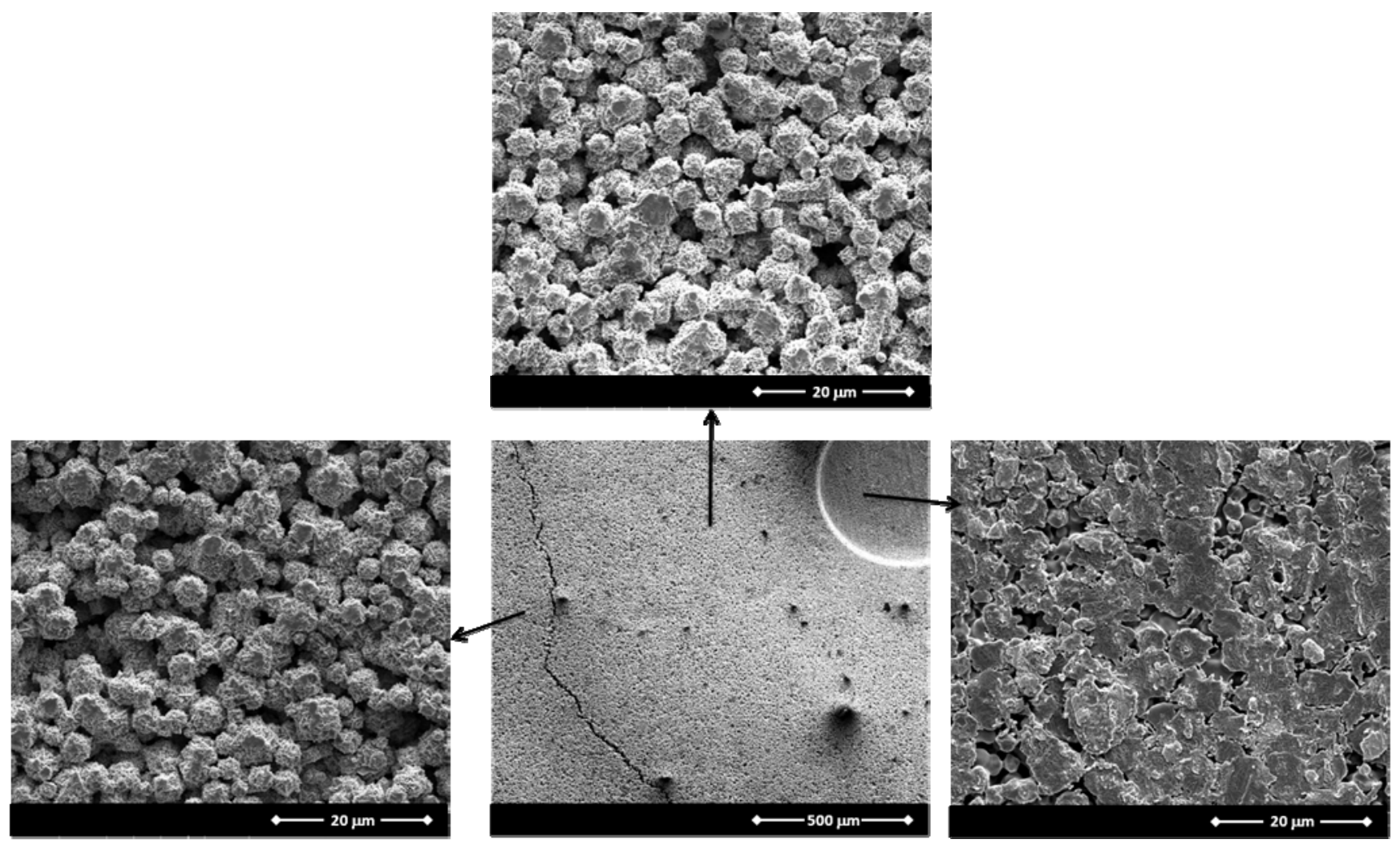

One useful parameter in sintering, especially when comparing specimens with different initial green densities (different initial porosity levels), is the densification parameter ( $\Psi$ ) [10] defined by Equation 1:

$$
\psi=\frac{f_{S-} f_{G}}{1-f_{G}}
$$

where $f_{S}$ is the fractional sintered density and $f_{G}$ is the fractional green density.

Figure 8 shows the average pore content (obtained through image analysis) at various locations at $150 \mu \mathrm{m}$ beneath the tip-surface interface for all specimens and it shows that for all three initial green densities, a final density of $\sim 0.85$ of theoretical was reached after $60 \mathrm{~s}$ of current exposure. However, if 
the densification parameter $(\Psi)$ (Equation 1) is considered, it is clear that it is inversely proportional to the initial green density.

Figure 8. Density (percent of theoretical) and densification parameter $\Psi$ for all investigated initial green densities (percent of theoretical).

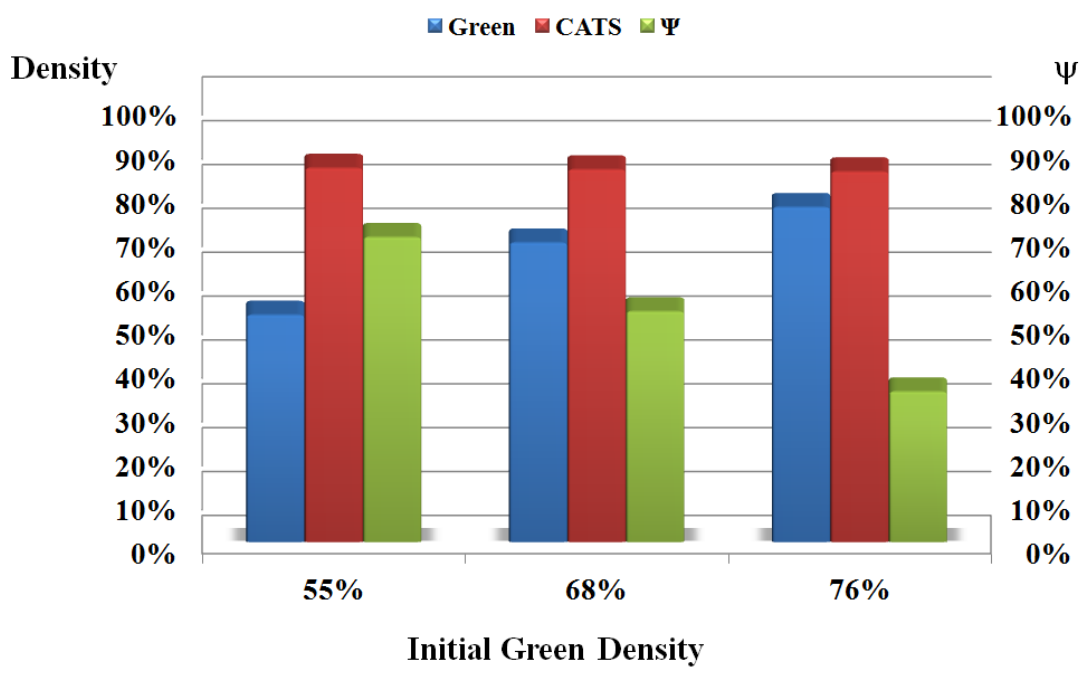

All results show that, despite having the lowest initial green density, the 55\% dense specimens observed the most significant and pronounced densification amongst all the specimens processed. Lower green density specimens are expected to have a lower electrical conductivity due to the presence of larger insulating air gaps and the minimum particle-to-particle contact areas [11], which enhances the Joule heating during current application. Furthermore, the assumed nominal current density (the applied current/the tip-material contact area) is in fact magnified as the actual contact area in powder compacts is less than the assumed area due to the presence of porosity and powder structure. In pressure-assisted powder densification, an effective pressure [12] is defined to take into account the powder/void structure of the material. For example, a fully consolidated material should result in an effective pressure equal to the applied pressure; however, a porous compact should result in a considerably higher effective pressure, generally due to a decline in the effective contacting area exposed to the same load. Although not previously reported to the best of the author's knowledge, it becomes also logical in the case of electric current activated sintering, to introduce an "effective current density" term $\mathrm{J}_{\mathrm{E}}$, analogous to the effective pressure, which should increase with a decrease in the initial green density. As such, the following equation can be introduced and may be assumed to represent effective current density, $J_{E}$.

$$
\frac{J_{E}}{J_{N}}=\left(\frac{1}{1-\theta^{\frac{2}{3}}}\right)
$$

where, $J_{N}$ is the nominal current density $=$ (current intensity/cross-sectional area) and $\theta$ is the fractional porosity.

Although all green density specimens were exposed to the same nominal current density, the initial effective current density is expected to be highest for the lowest density specimens (Figure 9). All the 
above factors (including effective current density and effective pressure) have contributed to the enhanced densification/consolidation behavior of the lowest density specimens.

Figure 9. Initial effective current density/nominal current density ratio for different investigated green densities.

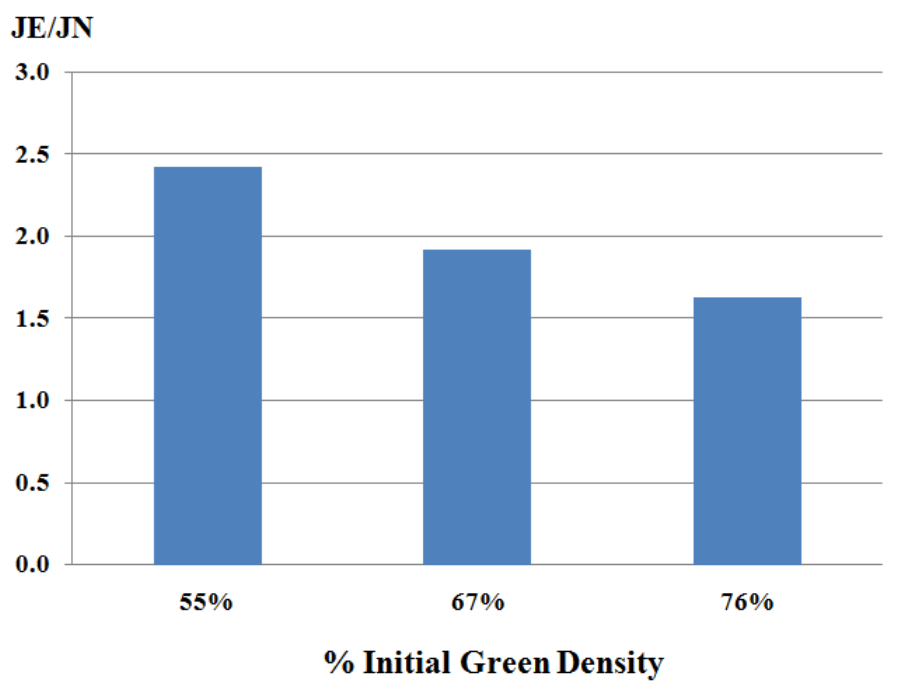

\section{Conclusions}

The following conclusions can be drawn from the present study:

1. Green compact temperature profiles were successfully generated for the first time in current-activated tip-based sintering under continuous DC current exposure.

2. The green density was found to have a major effect on the temporal and spatial temperature rise and distribution.

3. The lowest green density specimens resulted in the highest observed temperatures but more localized (closer to the tip) than higher green density specimens.

4. Despite all specimens attaining similar final relative densities following CATS, the 55\% initial green density specimens experienced the highest degree of densification according to densification parameter calculations.

5. At increased radial distance significantly removed from the process zone, specimens with lower initial green densities experienced a limited rise in temperature due to their lower thermal conductivity. This shows that localization of densification is enhanced by a reduction in initial green density. This could be exploited in future studies for micro-fabrication of complex structures under moving-tip configurations.

\section{Acknowledgments}

The authors wish to thank The National Science Foundation (CMMI division: grant no.0826532, Engineering Research Center: grant no.1028725, and major research instrumentation (MRI) grant DBI-0959908) for their support. Thank you also to Dr. Steve Barlow for his assistance with the FESEM work. The authors express their thanks to Mr. Marc Capul, Mr. Aliou Diallo and Mr. Ross 
Johnson for building the thermocouple-holding device. Thanks are also due to Mr. Greg Morris and Mr. Mike Lester for general technical support.

\section{References}

1. Mal'tsev, M. Electric rolling of powder materials with a dielectric phase. Powder Metall. Metal Ceram. 2003, 42, 225-229.

2. Mal'tsev, M. Electric rolling of metal powders in roller electrodes. Powder Metall. Metal Ceram. 2005, 44, 222-227.

3. Morsi, K.; El Desouky, A.; Johnson, B.; Mar, A.; Lanka, S. Spark plasma extrusion (SPE): Prospects and potential. Scr. Mater. 2009, 61, 395-398.

4. Morsi, K.; Essawi, A.M.K.; Borah, P.; Sayed, A.; Taher, M. Properties of single and dual matrix aluminum-carbon nanotube composites processed via spark plasma extrusion (SPE). Mat. Sci. Eng. 2010, 527, 5686-5690.

5. Morsi, K.; Moon, K.S.; Kassegne, S.; Ugle, R.; Villar, E. Novel current-activated tip-based sintering (CATS): Localization of spark plasma sintering. Scr. Mater. 2009, 60, 745-748.

6. El Desouky, A. Multi-Scale Current Activated Tip-Based Sintering of Powder-Based Materials. Ph.D. Dissertation, University of California-San Diego and San Diego State University, USA, 2012.

7. Patel, M.; Moon, K.S.; Kassegne, S.K.; Morsi, K. Effect of current intensity and cumulative exposure time on the localized current-activated sintering of titanium nickelides. J. Mater. Sci. 2011, 46, 6690-6699.

8. Numula, A.; Kassegne, K.S.; Moon, K.; Morsi, K. Current Activated Tip-Based Sintering of Ni-Al Intermetallics. Metallogr. Microstruct. Anal. submitted for publication, 2013.

9. El Desouky, A.; Moon, K.S.; Kassegne, S.K.; Morsi, K. Current Activated Tip-Based Sintering as a Micro-Fabrication Tool. In Proceeding of Europe PM2013 Congress \& Exhibition, Sweden, 15-18 September 2013.

10. German, R.M. Sintering Theory and Practice; Wiley: New York, NY, USA, 1996.

11. Lefebvre, L.P.; Pleizier, G.; Deslandes, Y. Electrical resistivity of green powder compacts. Powder Metall. 2001, 44, 259-266.

12. Jones, W.D. Fundamental Principles of Powder Metallurgy; Edward Arnold: London, UK, 1960.

(C) 2013 by the authors; licensee MDPI, Basel, Switzerland. This article is an open access article distributed under the terms and conditions of the Creative Commons Attribution license (http://creativecommons.org/licenses/by/3.0/). 